\title{
Selection of an effective topical corticosteroid
}

Tim Aung, Sandy Tin Aung

\section{Background}

There are different topical corticosteroid (TCS) agents and potencies available to treat various dermatological disorders.

There have been a number of publications on steroid phobia among general practitioners and patients, resulting in non-adherence and unresolved skin conditions, affecting patients' quality of life and healthcare costs.

\section{Objective}

The aim of this article is to discuss the process of selection of TCS for the treatment of a particular condition.

\section{Discussion}

It is crucial to choose the correct potency of TCS for treatment to avoid steroid phobia and undertreated conditions. TCS agents have different formulations, percentages and molecular structures, which affect potency, efficacy and effect. The adverse effects from TCS treatment are rare if the agent is correctly selected and applied. Patients can generally be treated effectively - without undesirable effects, steroid phobia and undertreated conditions - by factoring in patient and lesion characteristics, topical medication potency and method of application.
VARIOUS TOPICAL CORTICOSTEROID (TCS) agents and potencies are available for the treatment of dermatological disorders such as atopic dermatitis, contact dermatitis, psoriasis and lichenoid disorders in patients of all ages. However, studies have shown the existence of steroid phobia among non-dermatologist professionals (eg general practitioners [GPs] and pharmacists) as well as patients and parents, evidence of non-adherence and unresolved outcomes of skin conditions affecting quality of life and healthcare costs. ${ }^{1-8}$ Therefore, selection of TCS agents for effective treatment without undesirable effects is essential.

How simple is it, and what do we need to know to select the correct TCS for effective treatment of a particular condition? TCS agents have different formulations, percentages and molecular structures despite similar or near-similar names. These variations affect the potency, efficacy and effect. In addition, there are variable classification systems for the potency of TCS agents. ${ }^{9-12}$ Therefore, it is important to determine the potency of the TCS correctly for treatment. This article highlights the various potency categories of TCS agents for effective treatment of dermatoses from the general practice perspective.

\section{Topical steroid selection} and potency categories

The potency of TCS agents has been historically measured by the intensity of the vasoconstrictive effect. ${ }^{13}$ However, the specific molecular structure (eg betamethasone valerate or dipropionate), formulation (cream, ointment or solution) and percentage (eg $0.05 \%$ or $0.1 \%$ ) all affect the potency. In addition, the skin application site, use of an occlusive dressing and the vehicle (base) may alter or enhance the effect of the steroid, in accordance with the following general principles:

- Ointments penetrate skin slightly better than creams.

- Areas with thin skin (eg the face and eyelid) absorb medicine more readily than areas with thick skin (eg the trunk, limb, hand and foot).

- Intertriginous areas (eg the axilla, groin and breast folds) retain topical medications longer, with increased absorption. ${ }^{10,14}$

Thus, it is imperative to consider these factors along with the potency of the TCS for effective selection.

Regarding the classification of TCS potency, in 1997 the World Health Organization introduced class I (ultrahigh, the most potent) to VII (low, the least 
potent). ${ }^{9}$ However, some countries established a reversed order as well as use of several subdivisions with ill-defined words (eg low, weak, mild and medium in potency), leading to confusion for practitioners in complicated cases. Australasian guidelines favour the categories of mild, moderate, potent and very potent with corresponding classes I to IV, as shown in Table $1 . .^{1,3,12}$

Overall, the choice of potency will largely be guided by the following factors:

- patient: age (infant, child or adult) and lesion location

- lesion: type and severity of lesion (as described in Table 2)

- topical medication: molecular structure, percentage and formulation/vehicle

- method of application: occlusive dressing increases potency with better efficacy and effect, and wet dressing intensifies the effect by improved permeability of topical medication. Table 2 lists multiple skin conditions treatable with TCS agents. ${ }^{15-17}$

\section{Topical corticosteroid application}

With regard to choice of TCS formulation, an ointment base is preferred for dry, scaly and mucocutaneous lesions (eg on the lips and genitals); cream for wet/oozing lesions; and liquid (solution, lotion) for hairy areas (eg scalp), where cream or ointment is unable to reach the areas of affected skin.

The advice of applying TCS agents 'sparsely' is no longer applicable; instead, 'liberally' is encouraged. The required dose (amount) is guided by location and extent of the lesion (Box 1). The fingertip unit (FTU) is a useful general guide for the amount of topical agent (Figure 1). 1,3,14,18

It is highly recommended to use adjunct moisturisers/emollients following application of TCS agents to affected areas. The moisturiser can be applied locally or to the whole body to ease pruritus and irritation by maintaining optimum skin moisture. The moisture alone is also useful as a steroid-sparing agent in trivial dermatitis. Diluting the topical steroid with moisturiser does not change the potency of the medicine. ${ }^{12,14}$
Table 1. Classification of topical corticosteroid (TCS) potency in Australasia ${ }^{1,3,12}$

\begin{tabular}{ll}
\hline Potency & Corticosteroid \\
\hline Mild & $\cdot$ Hydrocortisone $0.5-1 \%$ \\
[Class I] & $\cdot$ Hydrocortisone acetate $0.5-1 \%$ \\
\hline Moderate (mid-strength) & $\cdot$ Clobetasone butyrate $0.05 \%^{*}$ \\
[Class II] & $\cdot$ Hydrocortisone butyrate $0.1 \%^{*}$ \\
& $\cdot$ Betamethasone valerate $0.02-0.05 \%$ \\
& $\cdot$ Triamcinolone acetonide $0.02-0.05 \%$ \\
\hline Potent & Methylprednisolone aceponate $0.1 \%{ }^{\dagger}$ \\
[Class III] & $\cdot$ Betamethasone dipropionate $0.05 \%$ \\
& $\cdot$ Betamethasone valerate $0.05-0.1 \%$ \\
\hline $\begin{array}{l}\text { Very potent } \\
\text { (ultra/super-potent) }\end{array}$ & Mometasone furoate $0.1 \%$ \\
[Class IV] & Clobetasol propionate $0.05 \%$ \\
\hline
\end{tabular}

Note: TCS agents unavailable in Australia are not listed here.

*Not available under the Pharmaceutical Benefit Scheme subsidy

tPlaced in the potent group by some countries
Table 2. Common skin conditions treatable with topical corticosteroid (TCS) agents ${ }^{15-17}$

\begin{tabular}{|c|c|}
\hline Mild (low) potency TCS & $\begin{array}{l}\text { - Dermatitis (face, eyelids, napkin area) } \\
\text { - Intertrigo } \\
\text { - Perianal inflammation }\end{array}$ \\
\hline $\begin{array}{l}\text { Mild-to-moderate } \\
\text { potency TCS }\end{array}$ & $\begin{array}{l}\text { - Atopic dermatitis } \\
\text { - Asteatotic eczema } \\
\text { - Contact dermatitis } \\
\text { - Dry nummular eczema } \\
\text { - Perianal inflammation (severe) } \\
\text { - Intertrigo (short term) } \\
\text { - Scabies (after scabicide) } \\
\text { - Seborrhoeic dermatitis }\end{array}$ \\
\hline $\begin{array}{l}\text { Moderate-to-potent/ } \\
\text { ultrapotent TCS }\end{array}$ & $\begin{array}{l}\text { - Atopic dermatitis (severe) } \\
\text { - Alopecia areata } \\
\text { - Contact dermatitis (severe) } \\
\text { - Eczema of hyperkeratotic, exudative nummular, hand and feet } \\
\text { - Granulomatous skin disorders - Granuloma annulare, } \\
\text { Necrobiosis lipoidica, and sarcoidosis } \\
\text { - Lupus erythematosus } \\
\text { - Lichen - simplex chronicus, planus and sclerosus } \\
\text { - Pemphigus and pemphigoid } \\
\text { - Psoriasis } \\
\text { - Stasis dermatitis } \\
\text { - Vitiligo }\end{array}$ \\
\hline
\end{tabular}

Note: Interchangeable choice of TCS with titration and response can be applied in some conditions as per description by factoring or specific local guidelines. Some hypertrophic/hyperkeratotic lesions might also require a combined intralesional steroid injection, which is beyond the scope of this article. 
Application is usually encouraged in the evening/night after bathing to avoid incidental removal of the medication as a result of day-to-day activities. In terms of frequency, a once-daily regimen is generally recommended for better compliance. Twice-daily application may be considered for the initial week(s) for certain severe lesions, reducing to daily or alternate-day application depending on the response.

An occlusive dressing with appropriate cover, such as a tubular bandage or plastic wrap, is favourable for severe and thick/ keratotic/lichenified lesions. Occlusion with a non-irritant glove or sock can also be used for lesions of the hand or foot, respectively. Close monitoring of occlusive or wet dressings is important to avoid undesirable effects from the reaction of occlusive materials and systemic absorption.

The duration of treatment depends on the type and intensity of the lesion; it is also guided by response to treatment, or follows a specific local guideline if available. It is advisable to discontinue or phase out application from daily to alternate-day, twice-weekly or weekend use over weeks or months (depending on the nature of residual lesion and recurrence) once the active inflammation/lesion has subsided. However, continued application of moisture should be encouraged.

Box 1. Dosage calculation of topical corticosteroids (examples guide; $1 \mathrm{FTU}=0.5 \mathrm{~g}$ )

- A child aged six years with face and neck involvement requires 2 FTU ( $1 \mathrm{~g})$ daily, and a $15 \mathrm{~g}$ tube of topical corticosteroid (TCS) would last two weeks.

- An adult with one leg and foot involvement requires 8 FTU $(4 \mathrm{~g})$ daily, and two tubes of $15 \mathrm{~g}$ TCS or one tube of $30 \mathrm{~g}$ would last one week.

- Greater quantities of the $15 \mathrm{~g}$ tube of potent TCS can be prescribed under the Pharmaceutical Benefits Scheme streamlined authority with the repeat, depending on the percentage of body surface involvement, which is to be calculated from rule of nines (similarly for burns).

\section{Adverse effects}

Topical steroids work via their anti-inflammatory, immunosuppressive and antiproliferative effects. Adverse effects, such as skin atrophy, striae, telangiectasia, easy bruising and hypertrichosis, are rare if TCS agents are used correctly. ${ }^{1,3,14}$ Periorificial dermatitis, steroid rosacea, red skin syndrome, contact dermatitis and pigment alteration are uncommon, and hypothalamicpituitary-adrenal axis suppression is extremely rare. Nevertheless, it is necessary to be mindful of iatrogenic Cushing's syndrome, growth retardation, cataract and glaucoma due to systemic absorption; such occurrence might be attributed to prolonged misuse of potent or ultrapotent TCS agents over large skin areas and/or occlusion causing increased systemic absorption, especially in susceptible individuals (young children and elderly patients with thin skin). ${ }^{14,19,20}$ In fact, adverse effects are more frequently reported in countries where higherpotency TCS agents are easily available over the counter or with the misuse of steroid in unregulated products. ${ }^{14,19,21}$ Adverse effects of TCS agents are generally reversible by cessation of

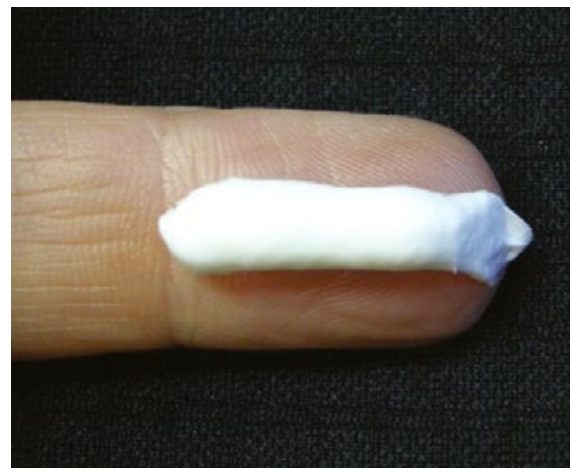

FTU of TCS; one FTU $\approx 0.5 \mathrm{~g}$ (the amount of topical steroid squeezed out from a standard tube $[5 \mathrm{~mm}$ nozzle] along an adult's fingertip from the very end of the finger to the first crease in the finger). Reproduced with permission from (c) DermNet New Zealand

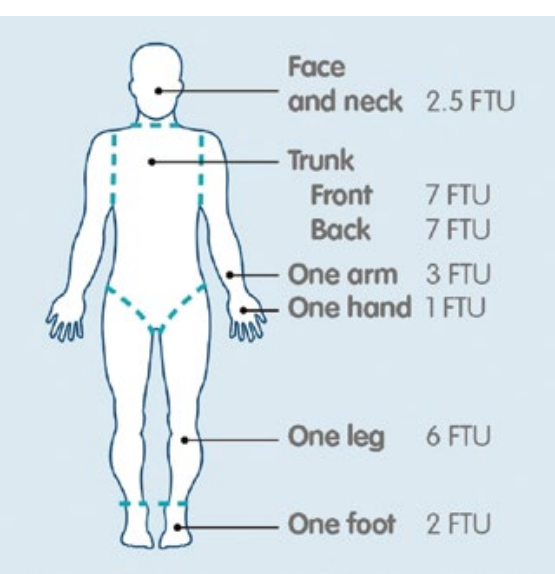

Amount of FTUs for different body parts in adults Reproduced with permission from (C) National Eczema Society 2020

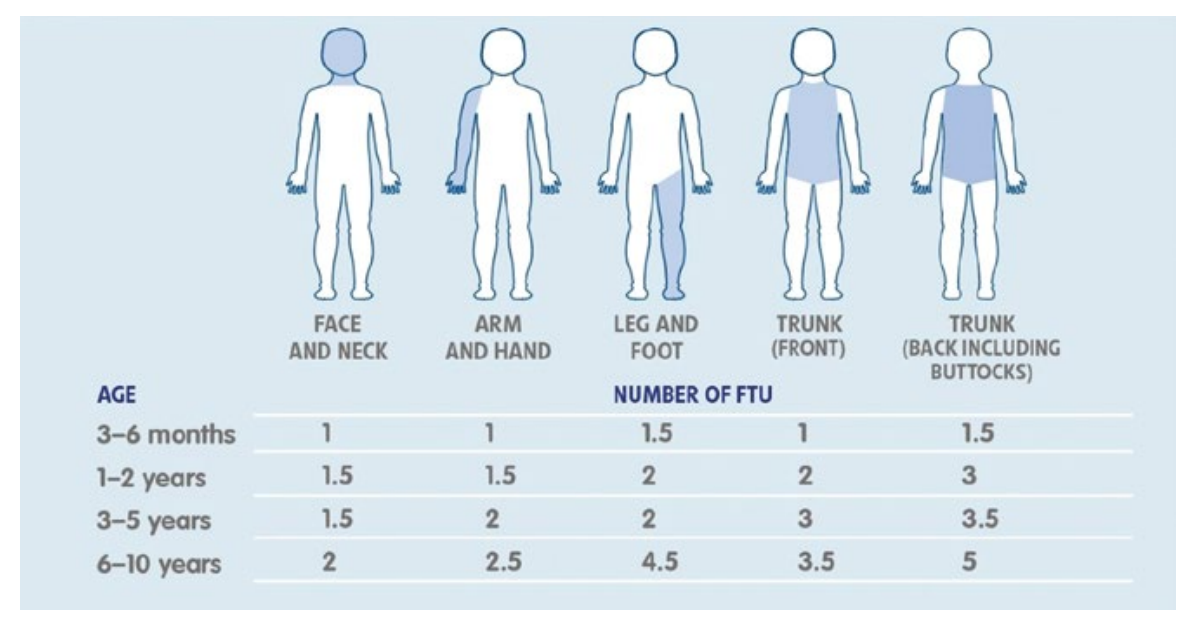

Amount of FTUs for different body parts in children

Reproduced with permission from (C) National Eczema Society 2020.

Figure 1. Fingertip units (FTUs) of topical corticosteroid (TCS) per application ${ }^{1,3,14,18}$ 
medication. Emerging evidence suggests that methylprednisolone aceponate and mometasone furoate are associated with lesser local and systemic adverse effects than older formulations of TCS because of their lipophilic structure and pharmacokinetics. ${ }^{22-25}$ Mild-to-moderatepotency steroids and short-term use of potent topical steroids are safe in pregnancy and lactation according to a systematic review (Chi et al). ${ }^{14,26}$

Overall, the benefits significantly outweigh any unwanted effects if TCS agents are correctly prescribed. Undertreated conditions are more widespread than overtreatment. ${ }^{1,3,12,14}$ Therefore, it is prudent for practitioners to properly educate the users to avoid non-adherence from steroid phobia, and undertreated conditions.

\section{Case examples with choice of topical corticosteroid}

\section{CASE 1}

A girl aged five years presented with dry atopic dermatitis of both hands. The dorsum hand location, which had some degree of scaling, was considered in selection of a TCS of moderate potencymethylprednisolone aceponate $0.1 \%$ ointment. One FTU to each hand with additional moisturiser cream nightly under non-irritant cotton gloves was applied. Total improvement was achieved in two weeks, and the patient's mother was advised to continue twice daily application of moisturiser to the patient's hands.

\section{CASE 2}

A young man aged 20 years presented with lichen simplex chronicus (thick, scaly and cracked skin) on the dorsum of the right foot, which had failed to respond to intermittent use of a mid-strength TCS. Treatment consisted of two FTUs of potent TCS (betamethasone dipropionate $0.05 \%$ cream) twice daily with an occlusive wet dressing (tubular bandage) for one week, followed by continuation of the potent TCS daily with occlusion at night after review. A satisfactory outcome was achieved in four weeks, and the patient was advised to continue the TCS twice weekly for a further eight weeks with the application of daily moisturiser to minimise recurrence. The patient was encouraged to apply daily sunscreen or moisturiser, and reassured that the skin, which displayed post-inflammatory hyperpigmentation, would return to normal colour in 3-6 months.

\section{CASE 3}

A man aged 55 years with penile lichen sclerosus presented with complications of fissures, pain and phimosis following failed treatment with mild-potency topical hydrocortisone $1 \%$ cream, prescribed by another institution one year ago. While waiting to be seen by a urologist for circumcision, he was treated with a potent TCS (mometasone furoate 0.1\% ointment, 0.5-1 FTU) twice daily for one week, and then daily after review. At six weeks, the skin had become normal in texture with no fissures, and the foreskin was able to be partially retracted.

In short, each case should be able to be treated effectively by factoring in patient and lesion characteristics, potency of TCS and method of application, as described in the 'Topical steroid selection' section. Complex or recalcitrant cases require referral to a dermatologist.

\section{Conclusion}

Ensuring the right potency of TCS by taking into consideration the relevant factors is important to avoid undertreating conditions of steroid-responsive dermatological disorders in clinical practice. It is apparent that the benefits from appropriate use of TCS appreciably outweigh the uncommon adverse effects.

\section{Key points}

- Careful selection of TCS potency by taking into account implicated factors is crucial for successful treatment of steroid-responsive skin conditions.

- It is prudent for GPs to effectively educate the users to avoid non-adherence from steroid phobia and undertreated conditions.
- TCS agents approved for a variety of dermatological disorders are safe and effective if correctly applied, and are also inexpensive.

\section{Authors}

Tim Aung FRACGP, FRNZCGP, Prof Dip in Gen Derm and Skin Cancer Surgery, Primary Care Practitioner, Brisbane, QLD

Sandy Tin Aung BPharm, Pharmacist, Logan Hospital, Queensland Health, Brisbane, QLD Competing interests: None.

Funding: None.

Providence and peer review: Not commissioned, externally peer reviewed.

\section{Correspondence to:}

timmynz2006@gmail.com

\section{Acknowledgements}

The authors are grateful to A/Prof Amanda Oakley CNZM, Dermatologist (FRACP, FNZDS), University of Auckland, and founder and former editor-in-chief of DermNet New Zealand, for reading and support.

\section{References}

1. Mooney E, Rademaker M, Dailey R, et al. Adverse effects of topical corticosteroids in paediatric eczema: Australasian consensus statement. Australas J Dermatol 2015;56(4):241-51. doi: 10.1111/ajd.12313.

2. Smith SD, Harris V, Lee A, Blaszczynski $A$, Fischer G. General practitioners knowledge about use of topical corticosteroids in paediatric atopic dermatitis in Australia. Aust Fam Physician 2017;46(5):335-40.

3. Best Practice Advocacy Centre New Zealand. Topical corticosteroids for childhood eczema: Clearing up the confusion. Dunedin, NZ: BPACNZ, 2016. Available at bpac.org.nz/2016/topicalcorticosteroids [Accessed 25 May 2021].

4. Aubert-Wastiaux H, Moret L, Le Rhun A, et al. Topical corticosteroid phobia in atopic dermatitis: A study of its nature, origins and frequency. $\mathrm{Br} J$ Dermatol 2011;165(4):808-14. doi: 10.1111/j.13652133.2011.10449.x.

5. Li AW, Yin ES, Antaya RJ. Topical corticosteroid phobia in atopic dermatitis: A systematic review. JAMA Dermatol 2017;153(10):1036-42. doi: 10.1001/jamadermatol.2017.2437.

6. Mueller SM, Itin P, Vogt DR, et al. Assessment of 'corticophobia' as an indicator of nonadherence to topical corticosteroids: A pilot study. J Dermatolog Treat 2017;28(2):104-11. doi: 10.1080/09546634.2016.1201189.

7. Alsukait SF, Alshamlan NM, Alhalees ZZ, Alsuwaidan SN, Alajlan AM. Topical corticosteroids knowledge, attitudes, and practices of primary care physicians. Saudi Med J 2017;38(6):662-65. doi: 10.15537/smj.2017.6.17586.

8. Le Roux E, Powell K, Banks JP, Ridd MJ. GPs' experiences of diagnosing and managing childhood eczema: A qualitative study in primary care. Br J Gen Pract 2018;68(667):e73-e80. doi: 10.3399/bjgp18X694529.

9. World Health Organization. WHO model prescribing information: Drugs used in skin diseases. Geneva, CH: WHO, 1997.

10. Gabros S, Nessel TA, Zito PM. Topical corticosteroids. In: StatPearls. Treasure Island, FL: StatPearls Publishing, 2020. 
11. British Association of Dermatologists. The British Association of Dermatologists' information on topical corticosteroids - established and alternative proprietary names, potency, and discontinuation. London, UK: BAD, 2015. Available at www.bad.org.uk [Accessed 25 May 2021].

12. The Australasian College of Dermatologists. The Australasian College of Dermatologists consensus statement: Topical corticosteroids in paediatric eczema. Rhodes, NSW: ACD, 2017 Available at www.dermcoll.edu.au/wp-content/ uploads/ACD-Consensus-Statement-TopicalCorticosteroids-and-Eczema-Feb-2017.pdf [Accessed 25 May 2021].

13. Humbert P, Guichard A. The topical corticosteroid classification called into question: Towards a new approach. Exp Dermatol 2015;24(5):393-95. doi: 10.1111/exd.12677.

14. Oakley A. Topical steroid. Palmerston North, New Zealand: DermnetNZ, 1997 (updated 2016). Available at https://dermnetnz.org/topics/topicalsteroid [Accessed 25 May 2021].

15. Ference JD, Last AR. Choosing topical corticosteroids. Am Fam Physician 2009;79(2):135-40.
16. Best Practice Advocacy Centre New Zealand. Topical corticosteroid treatment for skin conditions. Dunedin, New Zealand: BPACNZ, 2009. Available at https://bpac.org.nz/bpj/2009/september/ corticosteroids.aspx [Accessed 25 May 2021].

17. Aung T. Intralesional injection. Palmerston North, New Zealand: DermnetNZ, 2020. Available at www.dermnetnz.org/topics/intralesional-injection [Accessed 25 May 2021].

18. National Eczema Society. Topical corticosteroids factsheet. London, UK: National Eczema Society, 2019. Available at https://eczema.org/ wp-content/uploads/Topical-steroids-Sep-19-1. pdf [Accessed 25 May 2021].

19. Coondoo A, Phiske M, Verma S, Lahiri K. Sideeffects of topical steroids: A long overdue revisit. Indian Dermatol Online J 2014;5(4):416-25 doi: $10.4103 / 2229-5178.142483$

20. Nieman LK. Consequences of systemic absorption of topical glucocorticoids. J Am Acad Dermatol 2011;65(1):250-52. doi: 10.1016/j.jaad.2010.12.037.

21. Dhar S, Seth J, Parikh D. Systemic side-effects of topical corticosteroids. Indian J Dermatol 2014;59(5):460-64. doi: 10.4103/00195154.139874.
22. Mehta AB, Nadkarni NJ, Patil SP, Godse KV, Gautam M, Agarwal S. Topical corticosteroids in dermatology. Indian J Dermatol Venereol Leprol 2016;82(4):371-78. doi: 10.4103/03786323.178903.

23. Spada F, Barnes TM, Greive KA. Comparative safety and efficacy of topical mometasone furoate with other topical corticosteroids. Australas J Dermatol 2018;59(3):e168-e174. doi: 10.1111/ajd.12762.

24. Virgili A, Corazza M, Minghetti S, Borghi A Growing evidence for topical mometasone fuoroate in the treatment of vulvar lichen sclerosus. Maturitas 2015;80(1):113-15 doi: 10.1016/j.maturitas.2014.09.005.

25. Torrelo A. Methylprednisolone aceponate for atopic dermatitis. Int J Dermatol 2017;56(6):691-97. doi: 10.1111/ijd.13485.

26. Chi CC, Wang S, Kirtschig G. Safety of topical corticosteroids in pregnancy. JAMA Dermatol 2016:152(8):934-35. doi: 10.1001/ jamadermatol.2016.1009.

correspondence ajgp@racgp.org.au 